\title{
POBREZA Y ASISTENCIA SOCIAL EN LA ESPAÑA DEL SIGLO XVIII: LA CASA DE MISERICORDIA DE MURCIA (1700-1759)
}

\author{
José M. Sáez Gómez \\ Pedro Marset Campos
}

\section{Introducción}

Durante el siglo XVIII español se produce una evidente, aunque difícilmente cuantificable, expansión demográfica para cuya explicación pueden ser invocados el menor número de conflictos armados y la repatriación de las guarniciones militares de diversos puntos del Imperio, así como una disminución de la mortalidad epidémica. Sin embargo, hemos de suponer que, al igual que ocurre en el resto de Europa, el mayor peso de este crecimiento recae sobre la reducción de la mortalidad ordinaria y especialmente de la mortalidad infecciosa (McKeown, 1978).

Ello. es, sin duda, consecuencia de un cambio profundo de las relaciones sociales y de la consolidación del modelo de nación a lo largo del siglo XVIII, que permitiría una mayor coordinación y aprovechamiento de los recursos, mayor eficacia económica y una mejora sensible de la dieta alimenticia.

Este proceso causaría, en cambio, un desajuste entre un crecimiento económico relativamente lento y una rápida aceleración en el crecimiento de la población. En consecuencia, se crearía una población flotante de "va- 
gos y mendigos" que el sistema productivo, todavía con carácter feudal, sería incapaz de absorber hasta el inicio de la revolución industrial.

Los mendigos y vagabundos se estiman en el siglo XVII en unos 150.000 (Romero de Solís, 1973, págs. 40-41), aproximadamente un 2\% de la población, si aceptamos que el volumen total de la misma en los años 50 se sitúa en torno a los 7.300.000 habitantes, y su número debió seguir creciendo a lo largo del siglo XVIII dada la política de concentración de la tierra seguida por los Borbones. Su aumento fue tan importante que Felipe V crea una secretaría de levas, la cual se encarga de reclutar para el servicio de armas a los mendigos y vagabundos aptos, mientras el resto es encarcelado. La persecución fue continuada por Fernando VI y se recrudeció con Carlos III, a pesar de lo cual, en 1769, se cifra el número de vagabundos y mendigos en 200.000 (Romero de Solís, 1973, págs 42-43), es decir, todavía por encima del $2 \%$ de la población.

Las dimensiones del problema se multiplican si consideramos que la población española es en su inmensa mayoría rural, mientras que los marginados buscan su subsistencia en las ciudades, lo que provoca que su concentración en los núcleos urbanos sea en ocasiones alarmante.

Nos proponemos abordar el estudio de las soluciones que se aplicaron en Murcia à este fenómeno, soluciones que, según pensamos, corresponderán a un tipo de mentalidad en el que se debaten las incipientes ideas mercantilistas con las más tradicionales, y lejos todavía de las ideas salubristas que se desarrollan a partir de la segunda mitad del siglo XVIII.

\section{La población en Murcia}

Como en todo el mundo occidental, lo que caracteriza a la población de Murcia es su crecimiento. Entre 1650 y 1800, el volumen de la población murciana se multiplica por cuatro, pero hay que distinguir dos fases, una primera de recuperación, en la que se alcanzarán los niveles que ya existían a finales del siglo XVI y que culmina alrededor de 1690-1700; la segunda es una fase, a partir de esa fecha, de crecimiento continuado. En ambos casos el crecimiento es fundamentalmente de carácter rural (Pérez Picazo; Lemeunier, 1984, págs 134-141). La población calculada para la provincia y el Reino de Murcia en cada uno de los censos nacionales es, según Lemeunier (1980, pág. 25), la siguiente: 
Cuadro1. Evolución de la población en la provincia y reino de Murcia

\begin{tabular}{lrc}
\hline Años & Provincia & Reino \\
\hline 1694 & 82,770 & 112,502 \\
1717 & 84,764 & \\
1755 & 195,020 & 247,528 \\
1769 & 231,066 & 300,103 \\
\hline
\end{tabular}

Se hace necesario explicar los factores que inciden en esta evolución de la población, aunque no serán muy distintos a los que inciden a nivel general, puesto que resulta obvia una reducción de las tasas de mortalidad (Marset y cols., 1983, pág. 282; F. Chacón en Marset y cols., 1977, págs. 177-208) para la huerta de Murcia a falta de estudios más detallados por parroquias, con una desaparición más evidente aún de las crisis de mortalidad epidémica. La explicación está en la economía: la agricultura se desarrolla enormemente, llegando no sólo al autoabastecimiento, sino incluso permitiendo la exportación de ciertos productos; el comercio, aunque es todavía una actividad complementaria, experimenta un relanzamiento, y la artesanía puede desarrollarse gracias a la creciente demanda de sus productos (Pérez Picazo, Lemeunier, 1984, págs. 132-153).

La peste ha desaparecido y los nuevos sistemas de relación social y económica están haciendo sentir su efecto, lo que junto a una reducción de la emigración simultánea al incremento de la inmigración dan un saldo positivo de crecimiento, puesto que, como vimos, el coste humano que supone la Guerra de Sucesión es limitado. Este crecimiento, además, debió verse moderado por las circunstancias climáticas (Le Flem; 1982, págs. 100-101).

\section{Pobreza y asistencia social en Murcia}

El conjunto de circunstancias expuesto, hará que un problema constante en el municipio de Murcia lo represente la presencia de un número variable, generalmente amplio y en aumento en estos momentos de expansión económica; de personas sin oficio ni medios de subsistencia que 
deambulan por sus calles procurando su sustento con la mendicidad, el robo o la prostitución.

Si bien en los primeros años del siglo XVIII su número no parece representar un problema, sí lo será o al menos se toma conciencia de él a partir del segundo cuarto del mismo. La solución habría de venir de mano de la creación de una institución de acogida que, en un estricto régimen procurará alimentos, cama, vestido e incluso en ocasiones trabajo a una parte de ellos. Sin embargo, los propósitos no siempre consiguen llevarse a la práctica y la constitución definitiva del centro se verá retrasada por problemas fundamentalmente económicos.

\subsection{Los mendigos en Murcia. Primeros intentos de fundación de un} hospicio para pobres

España, como otros países en el siglo XVIII, tiene un auténtico problema por solucionar en el campo de la asistencia social a mendigos y desocupados, a los "vagos" que con frecuencia son reclutados para el servicio de las armas. El problema es similar al planteado en Inglaterra al surgir la necesidad de que la administración, desde el nivel estatal al municipal, se encargue de los pobres, y que da lugar a la Old poor law (Rosen, 1984, págs 53-80; Hollingsworth, 1986, págs. 15-19). Sin embargo, en el primer cuarto del siglo XVIII, Murcia no parece haber tenido excesivos problemas con vagos y mendigos. Los que no resultan aptos para las armas. pueden, de alguna forma, subsistir gracias a la caridad o son recluidos en las cárceles. Las levas de vagos y mendigos siguen siendo un alivio al gran número de ellos durante el resto del siglo. Pérez Estévez cifra estas levas en el reino de Murcia en las siguientes cantidades:

Cuadro 2. Volumen de las levas en Murcia

\begin{tabular}{lcccccccc}
\hline Años & 1734 & 37 & 42 & 45 & 46 & 59 & 60 & 64 \\
Vagos & 73 & 25 & 138 & 205 & 334 & 368 & 27 & 702 \\
$\%$ Habs (1) & 0,29 & 0,10 & 0,56 & 0,83 & 1,35 & 1,49 & 0,11 & 2,84 \\
\hline
\end{tabular}

Fuente: Modificado de Rosa M. Pérez Estéveż, en Flores Arroyuelo (1980b, 255) 
A partir de 1725-26; la situación parece haber empeorado y el Ayuntamiento va a intentar solucionarla con la fundación de una "Casa de Recogimiento para pobres", lo que no se consigue hasta 1739 por la negativa del Consejo de Castilla a conceder los permisos necesarios, pues considera que previamente se han de asegurar unos recursos económicos que permitan su subsistencia.

Los primeros intentos, como acabamos de apuntar, fracasarán: en febrero de 1726 se informa al cabildo que el Consejo de Castilla deniega el permiso (A. C. 26/2/26). En consecuencia se designarán comisarios que traten el tema con el Obispo y el cabildo eclesiástico con el fin de asignar estos fondos.

Aunque el regidor Juan Carrillo cederá para este fin una casa de su propiedad en la Parroquia de Sta. Eulalia (A. Ctas. Capitulares del Ayuntamiento de Murcia, 26/9/26: en lo sucesivo A.C.), las gestiones no progresan, nadie se decide a adelantar el dinero y Murcia recurre al Cardenal Belluga. La petición que se le eleva es que se aplique a este fin las rentas del Mayorazgo de Alcantarilla, el arbitrio de sosa y barrilla y cualquier otra disposición que el Cardenal considere adecuada (A. C. 11/1/27).

La petición no surte efecto y con el fin de

\begin{abstract}
“...evitar los pecados públicos a que con exceso y evidente riesgo vienen sujetos todos los hombres y mujeres que tienen libertad, corta edad y robusta salud, faltando gravemente a su obligación con clara contravención de los preceptos Divinos, eclesiásticos y leyes que se los prohíbe, sin tomar estado ni destino, fiados en la limosna diaria y en otros fines menos honestos para sus alimentos..." (A. C. 11/2/27),
\end{abstract}

en febrero de 1727 se decide recordar al "Padre de Pobres y Huérfanos" las obligaciones que tiene "desde tiempo inmemorial" y que, en lo que a pobres y mendigos se refieren, consisten en:

“Lo primero permitir que en esta ciudad solo pidan limosna para su alimento diario los hombres y mujeres naturales y vecinos de ella, constando de su naturaleza y vecindad, siendo ancianos o impedidos, no teniendo estos cualquiera de ellos patrimonio en hacienda de huerta, Campo, casas propias en su población, marido, mujer propia o padres que conforme a su obligación los deban alimentar y educar, porque a cualquiera que tubiere este refugio, absolutamente se le ha de prohibir." 
"Lo segundo no ha de permitir que los dichos hombres y mujeres naturales y vecinos de esta Ciudad, capaces de poder emplearse sirviendo, con ningún motivo ni pretexto pidan limosna en ninguna manera, porque antes si por todos los medios posibles bajo las órdenes que en caso necesario se le dieren y auxiliado de la Real Justicia, ha de proceder con el mayor rigor hasta obligarles, así hombres como a mujeres, a que sin ninguna dilación, cada uno en la parte y modo que le toca precisamente, se ponga a servir donde a expensas de su trabajo consiga las que necesita para sus alimentos, y si esta providencia ya empleada no bastare para que donde entraren a servir tengan una vida regular y en ella quietud y permanencia, dará cuenta para ocurrir a expelerlo del pueblo al que contraviniere esta disposición sin intermisión, por los graves inconvenientes que resultarán de lo contrario."

"Lo tercero, con especial aplicación y diligencia ha de inquirir diariamente por cuantos medios fueren capaces de conseguirlo, qué pobres viandantes entran en esta ciudad forasteros, y considerándole a cada uno de ellos tres días, uno el de su entrada y otro de descanso, en el tercero y último los ha de obligar precisamente a que salgan de esta ciudad, sin permitirles se detengan más tiempo en ella con ningún pretexto, y si alguno lo intentare dará cuenta para sủ remedio."

Además, los diputados de huerta y campo de la jurisdicción de Murcia quedan obligados a comunicar al Comisario y Padre de Huérfanos los casos similares que se p̈resenten en su diputación (A. C. 11/2/27).

Los párrafos que hemos reproducido textualmente son una muestra muy interesante del tipo de ideología dominante sobre el problema de la pobreza y la marginación; es evidente la responsabilización que se hace del propio individuo sobre su problema; y las medidas aplicadas son siempre de tipo coercitivo.

En 1729, Belluga propone que el Ayuntamiento ceda para asilo de pobres la Casa de Comedias; a cambio, el Cardenal ofrece tierras en el Campo de la Matanza, los arbitrios de sosa y barrilla y algún recurso más, prácticamente lo que el cabildo municipal solicitó dos años atrás, pero en esta ocasión la propuesta es rechazada (A. C. 5/3/29).

Así persiste la situación hasta 1739. El Padre de Huérfanos no ha conseguido controlar la entrada de vagabundos y Murcia se encuentra en plena epidemia de "tabardillos", que afecta principalmente, a decir del regidor Diego Zarzosa, a 
“...forasteros de la Mancha y otros pueblos que se han introducido en esta población sin oficio ni ejercicicio, de que resulta hallarse una cuarta parte de vecindario de gente forastera, aplicados a la limosna que el celo y caridad en lo general distribuye a los pobres..." (A. C. 28/4/39).

Es posible que la estimación del regidor resulte exagerada (¡ un 25\% de forasteros!), pero es al menos indicativa de que el problema está alcanzando enormes proporciones y refleja el fenómeno apuntado en la introducción de la concentración de los más desfavorecidos en los núcleos urbanos y de los movimientos migratorios del centro a la periferia ya iniciado en el siglo anterior.

A pesar de las resoluciones del Consejo de Castilla y advertencias del Ayuntamiento, los mendigos no son recluidos en la cárcel pues alegan "la imposibilidad del trabajo". Diego Zarzosa, propondrá de nuevo que no se permita pedir limosna a los forasteros, y que a los naturales de Murcia se les ponga

“...en el pecho insignia de tal pobre, la que esta ciudad destinase, con el escudo de sus armas, como en Sevilla y otras parte se hace."

Propone, además, que se nombren comisarios de los cabildos municipal y eclesiástico para volver a intentar poner en marcha la Casa de Misericordia (A. C. 28/4/39).

\subsection{La Casa de Misericordia. Primera época (1739-45)}

Finalmente, sin asignación de las rentas fijas que exigía el Consejo de Castilla (A. C. 20/3/45) y "fiados en la piedad cristiana", en el mes de octubre de 1739 se pone en marcha la Casa de Misericordia, pero la piedad cristiana fallará y la fundación desaparecerá en 1745 por falta de recursos económicos. Para el buen gobierno de la institución se redacta en 1739 un reglamento que se conserva impreso en tres páginas (Leg. 951, A. M. M.), el cual nos da idea de la estricta vigilancia a que se somete a los mendigos, incluidas las normas sobre el vestido. 
En cuanto a la alimentación es obligado hacer unas consideraciones: aún suponiendo que la ración teórica (Cuadro 3) se cumpla, el aporte diario no llega a 2.000 calorías, cifra límite para todas las edades y sexos con una vida medianamente activa ( 2 ).

Cuadro 3. Valor nutritivo de la ración diaria en la Casa de Misericordia de Murcia

\begin{tabular}{|c|c|c|c|c|c|c|}
\hline Producto & Cantidad & Proteinas & Lipidos & $H$ de $C$ & Calorías & Desperdicio \\
\hline \multicolumn{7}{|l|}{$\underline{\text { Comida }}$} \\
\hline Pan & 8 onzas & & & & & \\
\hline Carne & $\begin{array}{c}306,72 \text { gr. } \\
4 \text { onzas }\end{array}$ & 24,53 & 2,45 & 173,78 & 858,81 & \\
\hline & $153,36 \mathrm{gr}$. & 29,13 & 19,93 & 0,44 & 306,72 & 24,53 \\
\hline Hortalizas & 100 gr. (?) & 2,28 & 0,24 & 6,06 & 36,44 & 24,77 \\
\hline Fruta & 100 gr. (?) & 0,90 & 0,32 & 13,16 & 60,64 & 20,52 \\
\hline Vino & $\begin{array}{l}1 \text { ochavo } \\
54,16 \mathrm{ml} \text {. }\end{array}$ & & & & 41,70 & \\
\hline Cena & & & & & & \\
\hline Pan & $\begin{array}{c}4 \text { onzas } \\
153,36 \text { gr. }\end{array}$ & 12,26 & 1,22 & 86,89 & 429,40 & \\
\hline $\begin{array}{l}\text { Sopas ajo o } \\
\text { Gazpacho } \\
\text { Vino }\end{array}$ & $\begin{array}{c}? \\
1 \text { ochavo } \\
54,16 \mathrm{ml} .\end{array}$ & 9,00 (?) & 0,40 (?) & 38,87 & ?) 200,00 & \\
\hline Total & & 78,10 & 24,56 & 318,70 & $1.975,41$ & 69,82 \\
\hline
\end{tabular}

Fuente: Elaboración propia., Los datos proceden del reglamento de la Casa de Misericordia.

En cambio, el aporte proteico parece ser suficiente, puesto que se sitúa alrededor de los 78 gr., lo que sorprende tratándose de la fuente de calorías más cara. Pero como es lógico, la dieta se inclina hacia otra fuente de ener- 
gía, más barata, los hidratos de carbono, que aportan un 16\% más de las calorías que corresponden a una dieta equilibrada. También las proteínas están proporcionalmente en exceso, mientras que las grasas aportan una cuarta parte menos de energía de lo que les corresponde en una dieta equilibrada, como se muestra en el cuadro siguiente:

Cuadro 4. Equilibrio de la dieta en la Casa de Misericordia de Murcia

\begin{tabular}{lrrcrr}
\hline Principios & Aporte & Calorias & \% teor. calorías & \% real cal. & Diferencia \\
\hline Proteinas & 78,10 & 320,21 & 10 a 12 & 16,21 & 4 a $7 \%$ \\
Grasas & 24,56 & 228,40 & 35 & 11,56 & $-23,44 \%$ \\
H. Carbono & 318,70 & $1.306,67$ & 50 & 66,14 & $16,14 \%$ \\
Otros & & 120,13 & & 6,08 & $6,08 \%$ \\
\hline
\end{tabular}

Fuente: Elaboración propia.

Hemos comparado esta dieta con la que se administra en el Hospicio de Madrid, según Soubeyroux (1980, pág. 97), aunque el propio autor pone en duda que esta ración teórica sea realmente distribuida. Pero suponiendo que sus sospechas sean infundadas, observamos que las necesidades calóricas quedan cubiertas más ampliamente que en Murcia (se administran casi 2.600 calorías) y que la dieta es más equilibrada en principios inmediatos. De nuevo aquí llama la atención que, si alguno de ellos está en exceso, son las proteinas (aunque ligeramente menos que en Murcia), pero aún más extraño es que los hidratos de carbono aportan un $12 \%$ menos de lo que les corresponde en teoría. El alcohol aporta en el Hospicio de Madrid el 14\% de las calorías, frente al $6 \%$ de la Misericordia murciana.

La primera conclusión que se puede obtener es que, en la Casa de.Misericordia, si no se padece hambre se está muy cerca, y que los allí acogidos debían gastar prácticamente toda su asignación, producto del trabajo o de las limosnas, en complementar su pobre dieta, más aún si consideramos que la ración distribuida se ve recortada, según el reglamento, "las cuares- 
mas, viernes, sábados, vigilias y días de abstinencia", es decir, un mínimo de 140 días, más de la tercera parte del año.

Tras la fundación del hospicio y elaboración del reglamento, a 24 de diciembre de 1739 , la institución acoge ya a más de 200 pobres (A. C. 24/12/39), y al parecer se ha conseguido separar "los que son verdaderos de los viandantes y vagabundos". Para poder mantenerlos, el Ayuntamiento acuerda el 19 de septiembre de 1739 aumentar el precio de la libra de mujol de 24 a 32 mrs., así como la hueva de 8 a 10 y aplicar 1/4

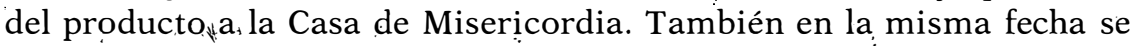
adjudica a la Misericordia 1/4 del arrendamiento de la encañizada (Leg. 951, A. M. M.).

El 7 de noviembre del mismo año se acuerda no cobrar el impuesto de un real por cabeza de carne que consume el establecimiento, tanto la de rafalí como la de venta en carnicerías, y el 10 de noviembre se le aplica el producto de las penas de ordenanza. El 24 de diciembre se libran 200 ducados de limosna, el 30 de enero de 1740 se libran 600 rs. a cuenta de lo que le corresponde por el mujol y el 22 de marzo se le adjudican 6 rs. por cada balcón de la Casa de Comedias que se ocupe durante la celebración de éstas (Leg. 951 y A. C. 7/11/39 y 24/12/39).

Por escritura otorgada en Roma ante D. José Ignacio Romano en fecha 18 de septiembre de 1741, el Cardenal Belluga divide en cuarenta porciones el total del producto de las Pías Fundaciones, asignando 1,5 partes a la Casa de Misericordia (Martínez Hernández, 1983, pág. 254; Flores, 1980a, pág. 8), a pesar de lo cual la fundación continúa teniendo problemas:

"Teniendo presente la Ciudad la falta de medios para la manutención de los pobres de la casa de misericordia, deseando subvenir a esta urgencia, acuerda que, por vía de aguinaldo, se despache libramiento de un mil y quinientos reales de vellón..." (A. C. 22/12/42)

En julio de 1743 siguen faltando recursos, pues además, el producto de la encañizada que debía percibir la Misericordia se ha empleado en reparaciones de la propia encañizada (A. C. 30/7/43), y se libra una limosna de 1.000 rs., que se cargará sobre el arrendamiento de la venta de nieve y agua fría (A. C. 3/8/43). En el mes de octubre, la situación se hace ya insostenible; merece la pena transcribir literalmente el informe que hace el corregidor del cabildo municipal (A. C. $8 / 19 / 43$ ): 


\begin{abstract}
"El Señor Corregidor hizo presente a la ciudad el miserable estado a que se halla reducido el hospicio y Casa de Misericordia, donde se acogen los pobres que lo son verdaderos, por haberse extinguido con esta providencia la numerosa multitud de vagantes, que infestaban el país, y aunque las celosas providencias de la junta formada para la perpetuidad de este establecimiento han sido las más eficaces, no han bastado para facilitar lo necesario a la diaria manutención, hallándose en el empeño de más de ocho mil Rs., y con la imposibilidad de poderlos satisfacer, motivos que han constituido a la junta en el mayor dolor, y más sensible el de haberse de extinguir el hospicio por falta de medios..."
\end{abstract}

En consecuencia, el Ayuntamiento propone la asignación de 500 ducados anuales sobre sus propios y rentas, solicitando para ello la aprobación del Consejo de Castilla, el cual no da respuesta, por lo que el cabildo insiste y solicita que la cantidad proceda del propio del matadero (A. C. 24/12/43). Ya en marzo de 1744, y tras una reunión del obispo con los comisarios de los dos cabildos de la ciudad, se reconoce como poco probable que la asignación sea autorizada, por lo que se hace una nueva propuesta en el sentido de que la misma cantidad se abone fraccionada en mensualidades, y que en caso de que esta alternativa tampoco fuera aprobada, sea el cabildo eclesiástico el que libre el dinero, iniciándose los pagos con efectos desde el primero de marzo (A. C. 17/3/44).

En junio llega una orden de S. M. fechada en Madrid a 30 de mayo de 1744 , en la que se pide un informe sobre las cuentas del hospicio para decidir sobre la asignación de 500 ducados. El Ayuntamiento acuerda remitir el informe y suspender la asignación a partir del primer día de julio (A. C: 16/6/44). En el mismo mes de julio, mientras se realiza el informe pedido por el rey, se celebra una reunión con el cabildo eclesiástico (A. C. 28/7/44), que se niega a asignar una cantidad determinada, aunque se ofrece a dar una limosna todos los años, sin señalar su cuantía ni el momento en que se haría efectiva (A. C. 29/12/44).

Ya en 1745, el Ayuntamiento insiste en la necesidad de determinar una cantidad por parte del cabildo eclesiástico. A cambio se ofrece a asistir a la Casa de Misericordia con "igual cantidad a la que se señalare por el referido cabildo y con la misma perpetuidad" (A. C. 28/7/44). Ante la falta de respuesta firme (A. C: $20 / 3 / 45$ ), el Ayuntamiento fija una nueva asignación, esta vez de 600 ducados, previo permiso del Consejo de Castilla y siempre y cuando el cabildo eclesiástico fije también su asignación (A. C. 6/4/45). 
Cuadro 5. Ingresos de la Casa de Misericordia de Murcia. Octubre 1739-31 enero 1745

\begin{tabular}{|c|c|c|c|c|c|c|}
\hline & \multicolumn{2}{|c|}{ Dinero } & \multicolumn{2}{|c|}{ Trigo } & \multirow[b]{2}{*}{$\%$ dinero } & \multirow[b]{2}{*}{$\%$ trigo } \\
\hline & Reales & $m r s$ & Fanegas & Celemines & & \\
\hline Sr. Cardenal & 120 & & 900 & & 0,11 & 22,14 \\
\hline Sr. Montes & 4.677 & .6 & 624 & & 4,50 & 15,35 \\
\hline Sr. Mateo & 4.113 & 24 & 761 & & 3,96 & 18,72 \\
\hline Cabildo Ecltc. $^{\circ}$ & 16.640 & 16 & & . & 16,02 & \\
\hline Ciudad Murcia & 18.641 & & . & & 17,95 & \\
\hline Comunidades & 965 & & 71 & & 0,92 & 1,74 \\
\hline Ecltc. $^{\circ}$ y multas & 7.800 & & 580 & 11 & 7,51 & 14,27 \\
\hline Secul. y multas & 16.746 & 33 & 1.126 & 6 & 16,12 & 27,71 \\
\hline Cepillos & 11.180 & 31 & & & 10,76 & \\
\hline Capachos & 4.878 & 6 & . & . & 4,69 & \\
\hline Entierros & 5.416 & 14 & & & 5,21 & \\
\hline Trabajo pobres & 737 & 6 & & & 0,70 & \\
\hline Total (3) & 103.843 & & .4 .063 & 5 & 100,00 & 100,00 \\
\hline
\end{tabular}

Fuente: Elaboración propia. Datos de A. C. 6/4/45.

En el cabildo ordinario del martes 6 de abril de 1745, y fechado en febrero del mismo año, se presentan las cuentas de los ingresos de la Misericordia desde su fundación hasta finales de enero de 1745, a lo que corresponde el cuadro que precede estas líneas. En estas cuentas, las limosnas de pan se consignan en trigo, y el resto de limosnas en dinero, a excepción de las ropas de vestir. El total asciende a 103.843 Rs. y 4.063 fanegas de trigo, destacando las aportaciones de los cabildos secular y eclesiástico, con el 18 y $16 \%$ de la aportación total respectivamente. Tiene la institución una media de ingreșos mensuales de 1.622,54 Rs y 63,49 fanegas de trigo, y unos gastos, en función de la deuda acumulada hasta octubre de 1743, equivalente a todos los ingresos más otros 167 Rs. mensuales. La Casa de Misericordia precisa, por tanto, para subsistir manteniendo: los ingresos de trigo, unos 1.789 Rs: mensuales (1952 ducados anuales), con lo que la aportación propuesta por el Ayuntamiento, de 600 ducados anuales, resulta totalmente insuficiente. 
La situación sigue sin cambios. En mayo de 1745 (A. C. 22/5/45), por medio de una carta, el cabildo eclesiástico afirmá que no puede comprometerse a asignar una cantidad determinada, pero asegura que sus limosnas nunca bajarán de los 600 ducados anuales. El Obispo, tras exigir unos nuevos estatutos (A. C. 5/6/45), da a escoger al Ayuntamiento.murciano entre dos formas de ayuda: treinta fanegas de trigo y un doblón (60 Rs.) por mes, más una cantidad que dependerá de las posibilidades de cada momento, o doscientas fanegas de trigo y 3.000 Rs. por año (A. C. 3/7/45). De esta forma se asegurarían, incluyendo la aportación del Ayuntamiento, unos ingresos entre los 1.200 y 1.500 ducados más 200 - 400 fanegas de trigo, todavía insuficiente, incluso suponiendo que no aumenten sus necesidades ni disminuyan las limosnas de particulares.

\subsection{La Casa de Misericordia. Segunda época (1752-1759)}

La consecuencia de todo lo señalado hasta el momento es obvia: la Casa de Miséricordia desaparece y no volvemos a tener noticias sobre ella hasta marzo de 1748 (A. C. 16/3/48), momento en que el Obispo consigue que el cabildo eclesiástico nombre cuatro comisarios para que reunidos con los del Ayuntamiento, intenten reinstaurar la institución, lo que no será posible hasta 1752, fecha en que se establece de forma definitiva, con la aparente resolución de sus problemas económicos a partir de diciembre de 1757.

En 1748 (A. C. 16/3/48), el cabildo municipal se compromete a aportar 500 ducados anuales

“... y así mismo correrá el aumento de dos cuartos en libra de mujol del que se coja en el propio de la Cañizada, aplicado al beneficio de dicha casa, o señalará por dicho aumento la cuarta parte del valor que tuviere por arrendamiento dicha Albufera [...] con la condición de que igualmente se ha de establecer renta o contribución fija por dicho Sr. Obispo y Cabildo Eclesiástico [...] y en caso de que en lo futuro por alguno se cese o retarde la consignación señalada, desde luego por parte de esta Ciudad se detendrá la suya o tomará aquellas providencias que le parezcan más conducentes."

También en esta ocasión, las conversaciones terminan sin fruto alguno. Habrá que esperar hasta marzo de 1752 (A. C. 4/3/52), fecha en que fallece 
el Canónigo de la Catedral Phelipe Mathias Munibe, que ha dejado todos sus bienes "a beneficio de los verdaderos pobres", para poner de nuevo en marcha la institución, con la aportación del Ayuntamiento en concepto de limosna de la cuarta parte del producto del arrendamiento de la encañiza$\mathrm{da}$, una vez descontados los gastos que produzcan en reparaciones y mantenimiento (A. C. 9/3/52), e incluso se nombrará, en el mes de julio, a un maestro de primeras letras para los niños acogidos en el hospicio, nombramiento que recae sobre Pedro Velasco.

Cuadro 6. Libramientos del Ayuntamiento de Murcia a favor de la Casa de Misericordia. 1752-1757

\begin{tabular}{rlr}
\hline Fecha & Concepto & Cantidad (mrs.) \\
\hline $23 / 12 / 52$ & Limosna & 3.000 \\
$3 / 7 / 53$ & Adelanto de su asignación & 51.000 \\
$24 / 12 / 53$ & Adelanto de su asignación & 51.000 \\
$27 / 1 / 56$ & Adelanto de su asignación & 74.800 \\
$23 / 7 / 57$ & Adelanto de su asignación & 204.000 \\
$24 / 12 / 57$ & Limosna & 3.000 \\
Total & & 386.800 \\
\hline
\end{tabular}

Fuente: Elaboración propia. Datos de las A. C. de 1752 a 1758.

Sin embargo, aún prosiguen las dificultades económicas y los administradores solicitan que se les concedan unos despojos del matadero (A. C. 15/4/52), y el Ayuntamiento se ve comprometido a continuas ayudas, librando así casi $180.000 \mathrm{mrs}$. en tres años, hasta enero de. 1756, como se aprecia en el cuadro precedente:

Por fin, en mayo de 1756, llegan las Reales Provisiones por las que se aprueba

“...la consignación sobre el propio de la encañizada; y un impuesto sobre la sosa y barrilla, todo para ayuda de la manutención de los pobres de la Casa de Misericordia..." (A. C. 29/5/56). 
Este último impuesto asciende a un real de vellón por quintal de sosa o barrilla producido o comercializado en el reino de Murcia. Ha de ser satisfecho por el comprador a excepción de aquellos núcleos de población en los que estos productos están cargados con otros impuestos. El Ayuntamiento acuerda, además, "tener intervención en el establecimiento de una obra pía de tanta importancia" (A. C. 1/6/56).

Parece que por fin se solucionan los problemas: las últimas ayudas que libra el Ayuntamiento son 3.000 mrs. de limosna y 6.000 a cuenta de su asignación, que a partir de diciembre de 1757 se librará regularmente.

\section{Asistencia sanitaria}

Mención aparte merece el tema de la asistencia sanitaria en la institución. Una constante en la actividad del concejo es intentar que los médicos de la Fundación del Doctor Espejo carguen con todo lo relativo a la asistencia a los pobres de Murcia, así como de los habitantes de la cárcel, la Casa de Misericordia y el Hospital, lo que sólo tiene éxito en parte al unir las plazas de médico del hospital con las de la Fundación, pero fracasa en lo que se refiere a la cárcel y Casa de Misericordia (4).

Los médicos de la Fundación del Dr. Espejo están en constante pleito con el Ayuntamiento por establecer unos límites a sus competencias. Los estatutos de la Fundación les exige hacerse cargo de la asistencia "a los pobres enfermos de las parroquias"; los médicos interpretan esta frase como que tan sólo deben atender a los pobres que no están internados en institución alguna y en base a ello se niegan a atender a los enfermos de la cárcel y, aunque de hecho ya se hacen cargo de la asistencia en el hospital, quieren delimitar sus funciones como médicos del mismo y de la Fundación. Estos problemas han llevado al Ayuntamiento a llamar continuamente a otros médicos para que atiendan a los reclusos, y éstos desean ahora regularizar su situación. Para ello elevan un memorial al cabildo en los siguientes términos (A. C: $1 / 12 / 42$ ):

"Al memorial de D. Joseph Bautista González y D. Esteban Martínez, médicos de esta Ciudad, diciendo que con el motivo de estar asistiendo muchos años a los pobres enfermos de la cárcel Real y a las torturas y otras urgencias con igual puntualidad y desinterés, y. que deseando continuarla, concluyen suplicando se digne esta ciudad de hacerles el nombramiento de tales médicos, así para continuar esta asistencia, como también 
para la de los pobres de la casa de misericordia. Y habiéndolo oído, teniendo presente el celo con que estas partes ofrecen continuar su asistencia a los pobres enfermos, de que resulta beneficio común, desde luego les nombra por tales médicos de ambas casas. Y se acordó se les de testimonio de este acuerdo para que les sirva de título."

De esta forma, la institución contará a partir de este momento con asistencia médica, y aunque en el nombramiento que se otorga a los médicos se especifica que no obtendrán remuneración, sí se les libra gratificaciones cuya cuantía no parece depender más que de la situación económica del Ayuntamiento en cada momento, puesto que si bien en 1739, dada la importancia de la epidemia de tabardillos padecida este año y el trabajo desarrollado por los médicos, la remuneración percibida es la más alta de todo el período (9.000 y $4.500 \mathrm{mrs}$ respectivamente para cada uno de los médicos), en la segunda epidemia en importancia, la de 1750, de carácter no determinado, tan solo perciben 1.500 mrs., la mitad de lo que es habitual que el Ayuntamiento decida como justo para recompensar la labor de los facultativos, y es además la cifra más baja registrada. La cantidad de $3.000 \mathrm{mrs}$. por médico, tan solo se ve alterada en los dos casos mencionados y en los años 1744 a 1746, en los que perciben 5.100 mrs. cada uno, y 1756 a 1758 con 2.610. En el siguiente cuadro se pueden apreciar los médicos que asistieron a la cárcel y Casa de Misericordia durante todo el período que estudiamos.

Cuadro 7. Relación de médicos que asisten a los enfermos de la carcel y Casa de Misericordia

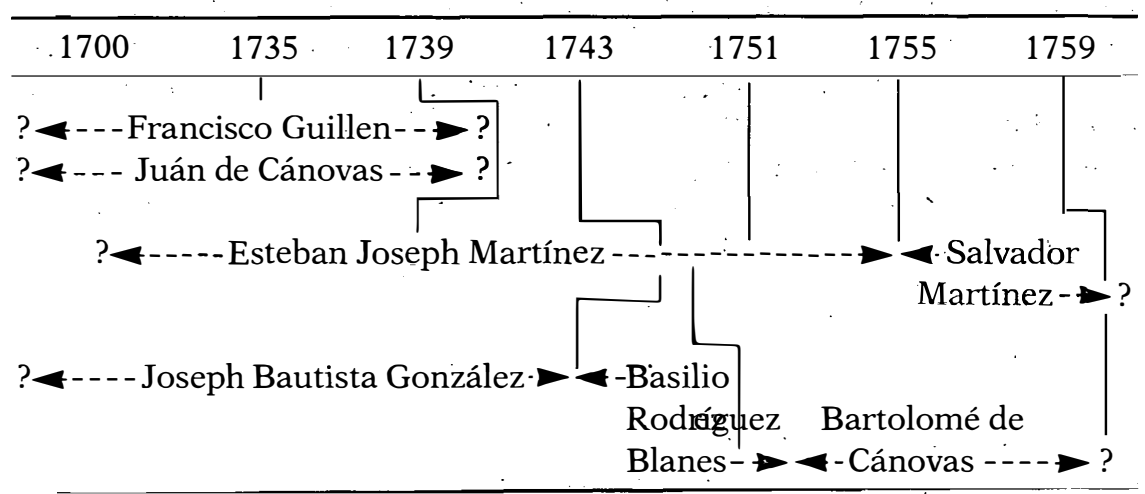

Fuente: Elaboración propia. 


\section{Conclusiones}

Murcia, cuya población había ido en aumento durante todo el siglo XVII, continúa sin interrupción el crecimiento durante el XVIII. El objeto último de la política sanitaria, la población, se va a ir convirtiendo, por tanto, en un problema cada vez más evidente. Problema, por otra parte, que se ve atenuado porque el crecimiento del XVII es, en realidad, una recuperación de niveles anteriores y por tanto sus necesidades pueden ser cubiertas, con mayor o menor eficacia, con la infraestructura y recursos ya existentes; solo a partir de 1690-1700 se inicia un auténtico crecimiento que exige una nueva inversión de recursos y plantea el problema de quién ha de hacerse cargo de aportar soluciones.

La asistencia a "vagos y mendigos" es totalmente inexistente al comenzar el siglo. Los sanos se ven encaminados al ejército y los enfermos al hospital, sin que el problema merezca mayor atención, puesto que, al parecer, no es excesivamente complicado por su número. A partir de 1725-26, al tiempo que van cambiando las concepciones sobre salud pública, la situación parece empeorar y se buscan soluciones más racionales y acordes con el nuevo pensamiento.

Observemos como, tal y como corresponde al pensamiento de la época, no se aborda en ningún momento el de la pobreza y la mendicidad como un problema público (salvo que cause molestias), sino privado (si se es apto para el trabajo, o si se puede ser mantenido por la familia, no hay justificación para la pobreza), y cómo si se aborda el problema desde instancias públicas es con una notable idea "caritativa" y con el fin de evitar los pecados "públicos"; por lo tanto es absolutamente normal que se reclame la participación de la Iglesia, tanto a nivel institucional (Cabildo Eclesiástico) como particular (Cardenal Belluga). Es evidente la convivencia entre la ideología cristiana y las incipientes ideas laicas y mercantilistas, que intentan encontrar una solución al problema de la sociedad (no al del marginado) obteniendo, si ello es posible, algún tipo de beneficio. La solución más inmediata es establecer un tratamiento "sintomático" a esta enfermedad social: si el síntoma es un excesivo número de mendigos, se buscará donde alojarlos, lo que se plasmará en la práctica con el intento de creación de una "Casa de Recogimiento para Pobres", que en 1726 no consigue la autorización del Consejo de Castilla para su puesta en funcionamiento al no haberle sido adjudicados los suficientes recursos económicos y que sin embargo, ante las dificultades que este requisito representa, sin asignación 
ninguna de recursos constantes, en 1739 el hospicio se pone en marcha y se redacta su reglamento.

El alto volumen de acogidos y los problemas económicos terminan por hacer inviable la experiencia y en 1745 la institución es clausurada, para ser reinaugurada en 1752 gracias al legado testamentario del Canónigo D. Phelipe Mathias Munibe, que deja sus bienes "a beneficio de los verdaderos pobres". Los problemas económicos de la institución se ven solucionados paulatinamente y los tres últimos años que comprende nuestro estudio parecen reflejar una relativa tranquilidad en este sentido.

Sin embargo, Murcia está todavía en una fase en que la asistencia benéfico-sanitaria depende en buena parte de fundaciones particulares. La asistencia sanitaria a los pobres de la ciudad es dispensada por dos médicos asalariados por la Fundación del Dr. Espejo, la Casa de Misericordia se constituye efectiva y definitivamente gracias al legado del Canónigo Munibe, la Casa de Expósitos dependerá de la asignación del Cardenal Belluga y buena parte de los ingresos del hospital son aportaciones de distintos particulares y entre ellas también las del omnipresente Belluga. Si la cárcel y la Casa de Misericordia, por otra parte, "cuentan con asistencia sanitaria es porque hay médicos dispuestos a trabajar gratuitamente a cambio de un nombramiento oficial y con la sola recompensa del prestigio adquirido y los ingresos que puedan representar las voluntarias ayudas del Ayuntamiento.

A pesar de todo, se observa en este período una concienciación progresiva entre los administradores murcianos en el sentido de que si bien no pueden adoptar soluciones definitivas, sí se puede actuar intentando paliar el problema, lo que además está manifestando una clara conciencia de que los temas de salud pública y asistencia social no deben ser una responsabilidad exclusiva de la Iglesia, proveedor habitual de estos servicios, sino que hay que dar paso a nuevos modelos de asistencia gestionados y organizados desde las administraciones públicas. Es interesante comprobar este estado de transición en el caso que estudiamos, en el que el Ayuntamiento intenta por todos los medios sacar adelante SU Casa de Misericordia, mientras es patente el convencimiento de que la Iglesia debe participar, de que toda institución de esta naturaleza debe ser mantenida y gestionada por la colaboración entre los estamentos civiles y eclesiásticos.

\section{NOTAS}

(1) Según censo de 1755 (Ensenada), de 247.528 habitantes.

(2) El cálculo de estos valores, lo hemos realizado, en los casos en que no conocíamos la cantidad exacta, suponiendo un aporte de 100 gr. de hortalizas y otros tanto de fruta. El 
valor nutritivo de estos alimentos se ha estimado obteniendo la media de 27 verduras y hortalizas y 17 frutas, las más frecuentes en nuestra región. Para el vino nos hemos basado en los precios de los años más próximos conocidos, 1721 y 1744, que es de $36 \mathrm{mrs} / \mathrm{azum}$ bre, según Cremadẹs Griñán (1984, 107, tabla 23). El valor del plato principal de la cena es una estimación personal.

(3) La media mensual es de 1622,54 Rs. y 63,49 fanegas de trigo, es decir, 8.12 Rs. y 0,22 fanegas de trigo por acogido, aceptando la cifra de 200 internos indicada en el A. C. de $24 / 12 / 39$.

(4) Sobre este tema, véase nuestro trabajo Sáez et al. (1988).

\section{BIBLIOGRAFIA}

1. CREmades GriÑ́n, C. M. (1984): Alimentación y consumo en la ciudad de Murcia durante el siglo XVIII. Murcia, Universidad.

2. Feldman, M. (1980): El siglo XVIII. Madrid, Cincel-Kapelusz.

3. Fernández de Pinedo, E. (1980): Coyuntura y política económicas, en TuÑón de LARA, M. (dir.). Historia de España. Centralismo, Ilustración y agonía del Antiguo Régimen (1715-1837), vol. 7. Barcelona, Labor, págs 11-173.

4. FLEM, J. P. LE (1982): Los aspectos económicos de la España Moderna, en TUÑoN DE LARA, M. (dir.): Historia de España. La frustración de un Imperio. vol. 5. Barcelona, Labor, págs. 9-133.

5. Flores Arroyuelo, F. J. (1980a): Guerra de sucesión en Murcia: Belluga. En: F. Chacón Jiménez (dir.), Historia de la Región de Murcia, vol. 7, Murcia. Mediterráneo, págs. 1-17.

6. Flores Arroyuelo, F. J. et. al. (1980b): Los días de la Ilustración: Socciedad y cultura, en Chacon Jiménez, F. (dir.): Historia de la Región Murciana, vol. 7. Murcia, Mediterráneo, págs. 107-313.

7. Goy, J. (1980): Del antiguo a un nuevo modelo demográfico, en Vovelle, M. (dir.): Historia Universal, vol. 6. Barcelona, Salvat, págs. 235-242.

8. Hollingsworth, J. R. (1986): A political economy of medicine: Great Britain and The United States. Baltimore; London. The Johns Hopkins University Press.

9. LemeunieR, G. (1980): Conquista agrícola y feudalismo desarrollado, en CHAcon JIMÉNEZ, F. (dir.): Historia de la Región Murciana, vol. 7. Murcia, Mediterráneo, págs. 19-77.

10. MaRSET Campos, P. et. al. (1977): La sociedad murciana y cartagenera y las epidemias durante los siglos XVII, XVIII y XIX. Asclepio, 29, págs 177-209.

11. Marset Campoś, P. (1983): Aspectos sanitarios de Murcia en los siglos XVIII y XIX. Una aproximación. Cuadernos de Historia, 10, págs. 279-301.

12. Martínez Hernández, A. (1980): Historia del Hospital Provincial de Murcia. Tesis Doctoral. Murcia. Facultad de Medicina.

13. MCKeown T. (1978). El crecimiento moderno de la población. Barcelona. Bosch.

14. Pérez Picazo, M. T.; Lemeunier, G. (1984): El proceso de modernización de la Región Murciana (siglos XVI-XIX). Murcia, Editora Regional. 
15. Romero DE Solis, P. (1973): La población española en los siglos XVIII y XIX. Madrid. Siglo XXI.

16. Rosén, G. (1984): La política económica y social en el desarrollo de la Salud Pública. Intento de interpretación. En E. LESKY (ed.). Medicina Social. Estudios y testimonios históricos. Madrid. Ministerio de Sanidad y Consumo, págs 53-80.

17. Sáez Gómez, J. M. et. al. (1988): El Hospital General de Murcia y los médicos de la Fundación del Dr. Espejo durante el siglo XVII. Actas del VIII Congreso Nacional de Historia de la Medicina. Murcia-Cartagena, 18-21 diciembre 1986, vol. 2, pp. 881-897.

18. Soubeyroux, J. (1980): Pauperismo y relaciones sociales en el Madrid del siglo XVIII. Estudios de Historia Social, 12-13, págs 7-229. 